\title{
9 Fostering Healthy Soils in California
}

\section{Farmer Motivations and Barriers}

\author{
Joanna Ory and Alastair Iles
}

\section{Introduction}

As the farmer walks down the tree row, she brushes past the cover crop that she planted several months ago. The truck that comes to pick up the bee boxes after the almond bloom is not due for two weeks, but the white almond blossoms are already falling to the orchard floor. She planted mustard and clover seeds so that bees would have food even after the almond bloom. Also, the mustard tap root will open the soil and let water soak in. When the cover crop grows taller, and the time nears for almond harvest, the vegetation will get mowed, and the plant material will break down, returning organic matter to the soil. This is a farmer with soil health on the top of her mind. What does it cost her, to follow these regenerative practices? More importantly, what does it cost us, if she does not?

Across the USA, many farmers face declining soil quality. The true costs of soil loss from farms include substantial water degradation and toxic exposure from nutrient and pesticide runoff. Pursuing soil health offers many benefits to farmers, including more fertile soil, increased productivity, higher crop quality, and other environmental and economic gains (Blanco-Canqui et al., 2015). Each season, farmers make decisions about whether to use soil-building practices like cover cropping, rotating crops, or using compost. This chapter looks at how almond farmers in California consider adopting soil health practices in an industry that emphasizes productivity and efficiency. What incentives and costs do farmers take into account? What motivations and barriers influence their ability to act? We discuss how use of True Cost Accounting (TCA) might help to change farmer behavior.

\section{Transitioning to Healthy Soils}

Only a minority of US producers have adopted soil health practices (Soil Health Institute, 2019). Less than 5\% of intensive vegetable farmers in the Central Coast in California use cover crops (Brennan, 2017). Such techniques are often not adopted by farmers because of market preferences, knowledge gaps, and agronomic, environmental, and policy barriers (Carlisle, 2016). 
Carlisle suggests that perceived long-term benefits, farmer knowledge and training, and stable land tenure are major factors that influence farmers to adopt soil health practices.

To make transitions, farmers, food companies, and policymakers need to understand the true environmental, social, and health costs associated with their production. This data alone will not necessarily persuade individual farmers to switch, because farmers might not experience the negative impacts that they cause. For example, farmers might not be aware that the erosion from their farms can cause water quality problems downstream. They also face significant barriers built into the economic and technological structures of their industry.

In this chapter, we demonstrate that many farmers are not implementing healthy soils practices owing to the perceived costs of trying to implement them, alongside an incomplete view of the external impacts caused by unsustainable farming practices. We highlight how farmers often miss out on soil health benefits because they are locked into production schedules, food safety standards, or "efficient" orchard management practices. Some of these barriers could be overcome by changing the dominant industrial supply chain, but this can be difficult to achieve. At present, farmers need to be extremely motivated to pursue improved soil health beyond making the minimal changes that the supply chain permits. Some innovative farmers are using more demanding practices because they are very committed to sustainability and soil quality. They are also sometimes isolated in their farming community, not knowing other farmers who are experimenting with soil health practices and lacking research in organic systems.

\section{Case Study of Almonds in California}

More than $80 \%$ of the world's almonds are grown in California. Almonds are the third most valuable agricultural commodity in California, amounting to $\$ 5.5$ billion in 2018 (California Department of Food and Agriculture, 2020a). Of this production, $67 \%$ is exported to other countries (Almond Board, 2019). Almonds are a permanent tree crop that usually spans 20 to 30 years of production before an orchard is removed. Since the 1950s, orchards have become larger, significantly mechanized, and less diverse in their varieties. Orchards are primarily a no-till system, which limits the ability of farmers to incorporate compost or other materials into the soil, whereas most annual vegetable cropping involves tilling or working with the soil every season.

A TCA of almond production includes examination of the impacts related to soil health challenges and mismanagement. Many farmers in the Central Valley of California have experienced drought and water scarcity, which have led to salt accumulation in the soil. Farmers have largely transitioned to high-efficiency drip irrigation, which allows for water use efficiency but limits the ability to grow cover crops, use compost, and nurture microbial life. Dust pollution from clearing orchard floors and during the harvest results in poorer air quality and public health in communities close to the orchards. Loss of habitat has undermined bee health and biodiversity. Farmers are evaluating the best options for disposing of 
old trees once the trees have reached the end of their productive life. Traditionally, farmers have burned trees on site or at cogeneration plants, but some are beginning to grind them up and incorporate the trees back into the soil-a process called orchard recycling.

For our case study, we interviewed 17 almond orchardists in the Central Valley, as well as industry and agricultural extension personnel. The growers we interviewed represent a spectrum of agricultural production types: from very large (thousands of acres) to small (less than ten acres), organic and regenerative to conventional farms, and market channels ranging from wholesale to direct-to-consumer.

\section{Putting Soil Health into Practice}

To build soil health, almond farmers might use techniques such as cover cropping, letting native vegetation grow between tree rows, applying compost, reducing equipment passes in the field to reduce compaction and dust, recycling old orchards, and integrating animals into the orchard. All of the growers we interviewed said that maintaining or improving soil health was important to them. Yet orchardists differed greatly in their adoption of soil-building practices, with some not taking any steps and others experimenting with many practices. Both motivations and barriers influenced the degree of adoption, and orchardists who were more prone to the adoption of soil health practices displayed more consciousness of the true costs of not using sustainable soil health practices.

The key motivations for implementing soil health practices that farmers cited can be grouped into three main categories: (1) environmental improvement; (2) yield and profitability; and (3) soil quality (Bergtold et al., 2017; Reimer et al., 2012). Regarding motivations for environmental improvement, one orchardist described their own true cost accounting related to healthy soil management, "You're looking at a whole systems approach. It's not just healthy soil, but healthy soil equals healthy plants, healthy animals, healthy humans, and a healthy environment for our water and our air." Farmers who care about environmental improvement often invoke ecosystem benefits and a keen awareness of the true costs of poor management on dust control and air quality, bee health, or carbon sequestration.

Those orchardists who emphasize yield and profitability refer to nutrient availability, disease prevention, and tree health as key outcomes of improved soil health. One interviewee noted: "Where compost is incorporated you can visibly see differences in the trees... They just look more vibrant. Greener. I mean the soil's healthier and so the trees are just happier. If you can be on a program doing it year after year keeping that soil balanced healthy-the trees will respond to it." Such orchardists link healthy trees with higher levels of production. This production-orientated set of motivations was more common among growers that used fewer soil health practices or used practices to remedy problem areas of the orchard but not throughout their land. 


\section{Cover Crops in Particular}

In orchards with no cover crop, the inter-row spaces are mowed and sprayed with herbicide to control weeds. The soil is bare, with little plant matter to enrich the soil or provide habitat. Compare this desolate orchard with one planted with clovers, mustard, and grass as a cover crop mix. There are flowers and lush ground cover. Bees, worms, and microbial life have a habitat. Water can percolate into the ground instead of pooling on the surface.

Cover cropping in California typically occurs at a very low rate compared with other US regions, largely because of the intensive commercial production system that we examine below. Planting a cover crop in an almond orchard involves planting seeds (often combinations of legumes, brassicas, and grass seeds) in the spaces between the tree rows and either relying on rain or sprinkler irrigation to water them. If the almonds are harvested off of the ground (which is the standard practice), the cover crop is typically grown until the spring, and then it is mowed and usually sprayed with herbicide to ensure a clean orchard floor for harvest.

\section{True Cost Accounting of Cover Crops}

True Cost Accounting (TCA) reveals many costs to the environment from not using cover crops, including ground compaction, water runoff and pollution off the farm, and reduced habitat (See Table 9.1 for a more in depth view of TCA for cover cropping). According to scientific research, cover crops offer many environmental and ecosystem benefits, including improved soil structure that inhibits erosion, more organic matter that encourages soil microbes (which in

Table 9.1 True Cost Accounting For Cover Crops in Almonds

\begin{tabular}{ll}
\hline Type of cost & Specific costs $(-)$ and benefits $(+)$ related to cover cropping in almonds \\
\hline Environmental & Bee health $(+)$, erosion control $(+)$, water infiltration $(+)$, \\
& increased soil microbiology $(+)$, increased ecosystem biodi- \\
& versity $(+)$, water quality improvement $(+)$, carbon storage $(+)$, \\
& reduced green house gas emissions $(+)$, herbicide use for ter- \\
& mination $(-)$ \\
& Dust reduction $(+)$, landscape beautification $(+)$, identification \\
& with environmental ethic $(+)$, worker well-being $(+$ or - \\
Social & depending on use of herbicide) \\
& Implementation of practice costs (time, labor, equipment, fuel, \\
& seeds) $(-)$, weed reduction $(+)$, cost savings from diminished \\
& synthetic fertilizer use $(+)$, impact on yield and production cost \\
& $(+$ or -$)$, long-term benefit of practice for soil health $(+)$, \\
& future impact costs in terms of soil health degradation of not \\
& using the practice $(-)$, possible fee from huller for debris in final \\
& raw product $(-)$, changing irrigation practices to accommodate \\
& practice $(-)$
\end{tabular}


turn boost tree root performance), improved nutrient cycling, reduced fertilizer use, and readier absorption of water into soil in an often-dry environment (e.g., Basche et al., 2014; Baas et al., 2015; Delate et al., 2015; Hu et al., 2015; Daryanto et al., 2018). In terms of farm performance, there can be substantially less runoff from fertilizers, fewer nitrogen emissions (which is important in the Central Valley owing to high prevailing air pollution there), and higher soil carbon sequestration. These multiple benefits are difficult to quantify in monetary terms.

Most orchardists interviewed had favorable views on cover cropping. They tended to focus on improved soil quality and orchard management. Often, orchardists would note multiple goals, especially to increase water absorption, improve bee health, increase microbial diversity, and provide dust control. Their goals also varied depending on the lifecycle phase of an orchard, whether it was too young to produce nuts, or it was mature, or it was close to reaching "old age."

Table 9.1 demonstrates the types of cost (and benefit) data that are necessary to develop the full picture for TCA for cover crops in almonds. The cost of not using practices should include the benefits the farmers - and the region-are missing out on in terms of natural, social, and human capital. Having specific evaluations for the different costs and benefits would be a useful decisionmaking tool for farmers and extension staff who provide recommendations to farmers.

\section{Motivations for Adoption}

True costs of not using cover crops, like ground compaction and water drainage problems, were prominent in motivating farmers to utilize cover cropping. Offfarm costs, like reduced carbon storage, were generally further removed from the motivations of most of the farmers we interviewed.

Many farmers said that they use cover crops to target areas of their orchards that have problematic drainage or erosion. One orchardist said, "We wouldn't necessarily think to put a cover crop on everything. We want cover crop on the areas where there are infiltration problems. You would put a cover crop with mustard seed in the ground to reduce compaction and standing water." Another orchardist explained, "For fields where we have some water penetration issues, we will plant [a cover crop] to try to help it, and we think it helps. It is an added cost but we feel like there's some benefits for problematic fields." A third farmer said, "I might plant a cover crop on one area where I have a nightmare of an erosion issue in part of the field." Cover cropping as a "fix" for orchard problems suggests that farmers are more motivated to invest time and money when they can see clear benefits from increased water savings and improved yields.

Organic farmers use cover crops to supply nutrients to trees. One organic orchardist mentioned, "Nitrogen is the deficit around here, so I use a mix that has root nodules that do the nitrogen fixation. I use some clover, vetch, 
beans and peas." Other farmers emphasized the importance of a cover crop for increasing soil microbe activity. For example, one grower stated: "Soil diversity more than anything [is the reason to cover crop]. To help the microbes with a place to survive longer." Not all farmers use cover crops-if they do at all-in their mature orchards. Several growers primarily planted cover crops in their young, non-nut producing orchards to enhance microbe communities, but once the orchard matures, they do not plant cover crops again.

One particularly interesting goal is offering bee forage during times when the almond trees are not in bloom. While bee hives are imported into the Central Valley on a vast scale, bees are locally active year-round, including in winter. Imported bees also need help to survive. One orchardist said, "Let's give the bees something not only to feed off when they arrive here because they get here before almonds start blooming. They need something to feed on after bloom season, the two weeks the beekeepers are trying to get everything out." The co-benefits of a cover crop for soil health and bee health underscore the multiple ecosystem services that some farming practices can provide.

Many orchardists who use cover cropping find that it helps with dust control. Because orchard floors tend to be kept bare to allow mechanized harvest, and exposed soils dry out in the Central Valley climate, dust during the harvest season is a major public health concern throughout the Central Valley. One orchardist remarked that the dust issue is something that needs to be seriously addressed by the almond industry. "The amount of dust we produce is almost embarrassing at times. We need to get better at it." Another farmer mentioned that "when it does not rain, the upper one inch and a half becomes dust right away because it is burned by the sun. Cover-cropping is great for dust control and for the workers because otherwise they can't see with the dust." The Almond Board (2018) - a business group that promotes this industry-has a goal of reducing harvest dust by $50 \%$ by 2025 . The Almond Board outlines a suite of steps that growers can take to reduce harvest dust, yet cover cropping is not currently included.

Most of the farmers linked better soil health back to healthier trees, increased yields, and greater farm revenues. Orchardists who greatly prioritize production are more willing to abandon practices if these do not clearly generate income. One orchardist commented, "Ultimately it has to come back to yield. If we don't improve our yield [we won't continue a practice]." This production oriented set of motivations was more common among growers that used fewer soil health practices or used practices to remedy problem areas of the orchard but not throughout their land.

\section{Barriers to Using Cover Crops}

Many farmers we interviewed did not practice cover cropping themselves or did so only on a very limited part of their operation. We found that major barriers to orchardists using cover crops include (1) concerns about water use; 
(2) incompatibility of cover crops with production schedules and equipment; (3) costs of implementing cover crops; (4) food safety requirements; (5) lack of market support; and (6) an incomplete view of the true costs associated with not cover cropping. We focus on a few examples here. These barriers must be factored in when considering how TCA might help farmers to transition to soil health.

Planting cover crops is not cost-free: orchardists must pay for seed, the equipment, labor, and fuel to plant the seed, the cost of water to irrigate the cover crop (if it is not rainfed), and the time and fuel (and possibly herbicide) needed to terminate the cover crop before harvest. Farmers must learn which mixes of cover crops work best for their land and how to grow cover crops (which could be different for an orchardist who is primarily used to tree care).

Farmers often said that they did not want to plant cover crops owing to lack of rain/irrigation water to grow the cover crop. Many parts of the Central Valley experience low rainfall, and farmers depend on California's vast water infrastructure or their own groundwater to irrigate crops. The issue of water unavailability is evident for farmers who use only drip irrigation, and do not have the option of using sprinkler irrigation to water the cover crop. The drip irrigation situation means that growers must rely on rain to sustain a cover crop, which is difficult during years with little precipitation. One orchardist said that he would not plant a bag of cover crop seed for the 2019 season because he did not want to waste the seed, owing to drought.

Overcoming this barrier, which is both technological (the type of irrigation system) and environmental (availability of rain) does not have an easy solution. For example, one farmer said: "One of the things we would love to do here and it just has not worked, we spend money and it has not worked, is grow a cover crop. The rains have not come at the times when we needed them. It just hasn't worked out. It's cost us money for really no gain." However, some farmers have been experimenting with different seed mixes that might not require as much water.

The industrial production system and supply chain is another barrier. Many orchards rely on contracts with buyers, where farmers are paid to produce high yields from the orchards without much concern for production methods or sustainability impacts. One family farmer commented: "The corporate farms are perfect and clean and use lots of chemicals. The people who take care of farms, the people that they're growing for, they do whatever they have to do as contract work for that investment group. They want to keep their jobs, and their job is to grow the nuts and they will do that with a lot of inputs." Conventional orchardists tend to stick to production schedules and to worry about cover crops interfering with the almond harvest. For example, a cover crop must be terminated and cleared in time to allow harvest machines to be used. Cover crops that are mowed can leave behind debris that pose food safety problems if nuts are gathered from the ground. For many orchardists, it is much easier and cheaper to use pesticides rather than mow.

Finally, few market incentives exist for orchardists to use cover crops in the industrial supply chain. Almonds are generally pooled together at the processing plant where they are shelled and hulled. Many buyers have little interest in-and 
input into-the production practices used at the farm level, and little contact with actual producers. Practices that protect soil health are often not valued or even discussed in the supply chain. One grower involved in the wholesale market explained: "My almonds end up in the Almond Complex. I don't think the buyers are asking so much [about sustainability], like are these organic or regenerative? I don't think they're selling to people who are asking for that. This is not the industry that is asking for specific types of almonds."

TCA could be used as a tool within the supply chain to evaluate the sustainability of the almond industry. Creating closer links between consumers, buyers, and producers would be a step in strengthening transparency about sustainability issues within the supply chain. The Almond Board currently runs a sustainability program for farmers to perform self-assessments. Including a TCA tool as part of this sustainability program — and increasing buyer awareness and demand for participation in the program-could help the supply chain to focus on the costs and benefits both on and off the farm for different practices.

Sustainability initiatives that take into account the true costs of agricultural production are becoming more common within food and farming industries. While initiatives like bee- or bird-friendly production are growing in popularity, soil health is not usually a major aspect of sustainability programs. For example, almond milk producers work with farms on different sustainability measures, particularly water efficiency and bee health, although soil health is not part of their initiatives. However, some food companies are starting to show interest in regenerative agriculture and working with farmers to supply regenerative almonds. One interviewee stated, "We work with a (specific food company, name withheld) because they want to find somebody that they can source almonds from that's raising almonds regeneratively. That's very much a concern for them. It's not for everybody, though." Increasing awareness of the externalities related to soil management among food buyers could put more pressure on growers to adopt practices that support soil health.

\section{Valuing Soil Health Through Innovative Policy}

Several US Department of Agriculture and California government agri-conservation programs have contributed to the growing uptake of health practices through incentives and technical advice. These programs include the Environmental Quality Incentive Program and the Conservation Innovation Program at the US Department of Agriculture's Natural Resources Conservation Service. These programs are under-resourced and routinely over-subscribed. Many farmers in California might not gain access to the resources. It is also unclear whether and how the programs influence farmers to diversify and to successfully protect soils. In response, in 2017 California created the Healthy Soils Program, administered by the California Department of Food and Agriculture (CDFA), which seeks to incentivize farmers to pursue healthy soils.

This program offers farmers up to three years of funding to introduce one or more soil health practices on land where the practices have previously not been used (California Department of Food and Agriculture, 2020b). A key factor in 
CDFA's determination of whether a practice is eligible is whether it stores carbon. To date, hundreds of farmers, including a few almond orchardists, have received grants. For the 2020 grant round, the CDFA awarded over $\$ 22$ million in grants. The individual grants are up to $\$ 100,000$ per farm. Interviewees saw financial incentives as a way to minimize the risks of using practices on large acreage. A measure of program success will be whether farmers continue to use the practices after their grants end. Will they become more willing to invest in soil health?

While incentive programs like the HSP could expand adoption of soil health practices, the inclusion of TCA tools for farmers would strengthen these programs. The HSP would improve if it not only considered greenhouse gas emission reduction benefits when valuing different agricultural practices, but also included protecting water quality, reducing soil erosion, and maintaining healthy agro-ecosystems.

\section{Conclusion}

Increasing soil health practices calls for many changes to the current agricultural system. Enabling farmers to see and act on the long-term benefits of soil health for their land is a necessary step. TCA offers a valuable tool for farmers and others to understand the ways in which adopting or not adopting certain practices affects their profitability, environment, and communities. To further strengthen this insight, TCA should include the missed benefits from being unable to carry out practices due to economic, technological, and production barriers. To overcome current policy and market barriers, policymakers, buyers, and consumers also need to value soil health practices much more.

\section{Funding Acknowledgment}

Thank you to the Berkeley Food Institute, USDA AFRI Grant \#2019-6701929537, NSF Award \# 1824871, and Patagonia, Inc. for supporting this research.

\section{References}

Almond Board of California. (2018). Almond Orchard 2025: Reducing harvest dust. Available at: www.almonds.com/sites/default/files/content/attachments/Almond\% 20Orchard\%202025\%20Reducing\%20Dust\%20at\%20Harvest.pdf.

Almond Board of California. (2019). Almond Almanac 2019. Available at: www.alm onds.com/sites/default/files/2020-04/Almanac_2019_Web.pdf.

Baas, D., Robertson, G., Miller, S., \& Millar, N. (2015). Effects of cover crops on nitrous oxide emissions, nitrogen availability, and carbon accumulation in organic versus conventionally managed systems. Final report for ORG project 2011-04952. CRIS Abstracts.

Basche, A., Miguez, F., Kaspar, T., \& Castellano, M. (2014). Do cover crops increase or decrease nitrous oxide emissions? A meta-analysis. Journal of Soil and Water Conservation, 69(6), 471-482. https://doi.org/10.2489/jswc.69.6.471. 
Bergtold, J.S., Ramsey, S., Maddy, L., and Williams, J.R. (2017). A review of economic considerations for cover crops as a conservation practice. Renewable Agriculture and Food Systems. 34, 1-15. https://doi.org/10.1017/S1742170517000278.

Blanco-Canqui, H., Shaver, T.M., Lindquist, J.L., Shapiro, C.A., Elmore, R.W., Francis, C.A., Hergert, G.W. (2015). Cover crops and ecosystem services: insights from studies in temperate soils. Agronomy Journal, 107(6), 2449-2474. https://doi.org/10. 2134/agronj15.0086.

Brennan, E. (2017). Can We Grow Organic or Conventional Vegetables Sustainably Without Cover Crops? HortTechnology, 27(2), 151-161. https://doi.org/10.21273/ HORTTECH03358-16.

California Department of Food and Agriculture. (2020a). California Agricultural Production Statistics. Available at: www.cdfa.ca.gov/statistics.

California Department of Food and Agriculture. (2020). Healthy Soils Program. Available at: www.cdfa.ca.gov/oefi/healthysoils.

Carlisle, L. (2016). Factors Influencing Farmer Adoption of Soil Health Practices in the United States: A Narrative Review. Agroecology and Sustainable Food Systems, 40(6), 583-613. https://doi.org/10.1080/21683565.2016.1156596.

Daryanto, S., Fu, B., Wang, L. Jacinthe, P., \& Zhao, W. (2018). Quantitative synthesis on the ecosystem services of cover crops. Earth-Science Reviews, 185, 357-373. doi:10.1016/j.earscirev.2018.06.013.

Delate, K., Cambardella, C., \& Chase, C. (2015). Effects of cover crops, soil amendments, and reduced tillage on carbon sequestration and soil health in a long term vegetable system. Final Report for ORG project 2010-03956. CRIS Abstracts.

Hu, S., Shi, W., Meijer, A., \& Reddy, G. (2015). Evaluating the potential of winter cover crops for carbon sequestration in degraded soils transitioning to organic production. Project proposal and final report for ORG project 2010-04008. CRIS Abstracts.

Reimer, A, Thompson, A., \& Prokopy, L. (2012). The multi-dimensional nature of environmental attitudes among farmers in Indiana: Implications for conservation adoption. Agriculture and Human Values, 29(1), 29-40.

Soil Health Institute. (2019). Progress Report: Adoption of Soil Health Systems Based on Data from the 2017 US Census of Agriculture. Available at: https://soilhealthin stitute.org/wp-content/uploads/2019/07/Soil-Health-Census-Report.pdf. 